\title{
Evaluación de Tecnologías Sanitarias: Eficacia de la vacuna para el virus del papiloma humano
}

Efficacy of the human papillomavirus (HPV) vaccine

Cortesía del Instituto de Efectividad Clínica y Sanitaria: www.iecs.og.ar

\section{Contexto clínico}

Los papilomavirus humanos (HPV) tienen alta prevalencia en todas las poblaciones. Existen más de 30 tipos que infectan las mucosas, incluyendo el epitelio ano-genital. Hay tipos de alto riesgo (oncogénicos o asociados al cáncer) como el 16, el 18, el 31 y el 45 y de bajo riesgo (asociados con lesiones no cancerosas como las verrugas genitales) como los tipos 6 y 11 . Aunque en las últimas décadas el uso del rastreo con el test de Papanicolau (PAP) ha reducido la incidencia de cáncer cervical en un $70 \%$, continúa siendo el segundo en frecuencia a nivel global en mujeres. Por ejemplo, en Argentina, en 2004, la tasa de mortalidad por cáncer de cuello uterino fue de 7,85 por cada 100.000 mujeres mayores de 20 años. Se postula que la prevención con la vacuna podría prevenir la mayoría de las lesiones de alto grado precancerosas y los cánceres invasivos.

\section{La tecnología}

La vacuna está elaborada a partir de partículas no infecciosas del HPV. El laboratorio Glaxo elaboró una vacuna bivalente que cubre los subtipos de HPV que causan el $70 \%$ de los cánceres cervicales (HPV 16 y 18) y el laboratorio Merck, una tetravalente que suma a la precedente la protección contra dos tipos que causan el $90 \%$ de las verrugas genitales' ${ }^{1}$.

\section{Objetivo}

Evaluar la eficacia vaccinal de la vacuna contra HPV.

\section{Métodos}

Se realizó una búsqueda en las principales bases de datos bibliográficas, en el sitio web del Centro para las Revisiones y Diseminación de York (CRD) Medicare y Medicaid estadounidenses, en buscadores genéricos y meta-buscadores de Internet, en agencias de evaluación de tecnologías sanitarias y financiadores privados de salud. Se buscaron revisiones sistemáticas, meta-análisis ensayos clínicos controlados aleatorizados, estudios observacionales, evaluaciones de tecnologías sanitarias, guías de práctica clínica y políticas de cobertura de otros sistemas de salud. Se priorizaron revisiones sistemáticas y los ensayos clínicos aleatorizados (ECA) pero también fueron incluidas revisiones narrativas y series de casos. Se consultaron los sitios "web" de las principales sociedades y asociaciones locales y estadounidenses vinculadas con el tópico.

\section{Resultados principales}

\section{Vacuna bivalente (tipos 16 y 18 )}

La eficacia de la vacuna se evaluó en un ECA doble ciego ${ }^{2}$, controlado contra placebo en 1113 mujeres de 15 a 25 años, realizado en EEUU, Canadá y Brasil. El seguimiento fue de 4,5 años. La seroconversión ocurrió en $95 \%$ de las mujeres. La protección contra la infección persistente (mayor a un año) ocurrió en el $100 \%$ de las mujeres que recibieron la vacunación (IC 95\% 33,6-100) mientras que la eficacia para la prevención de la infección incidente (nueva infección) fue de 96,9\% (IC $95 \% 81,3-99,9$ ). Más del $99 \%$ de las pacientes vacunadas sostuvieron el nivel de anticuerpos protectores por más de 4,5 años, para ambos tipos virales estudiados. No se registró ningún caso de neoplasia intraepitelial cervical (CIN) en el grupo vacunado, mientras que fueron ocho los casos reportados en el grupo placebo.

En otro estudio, en 776 mujeres de 15 a 55 años con un seguimiento a 4,5 años, la vacuna bivalente mostró resultados similares incluyendo mujeres del subgrupo de mayor edad (46 a 55 años).

\section{Vacuna Tetravalente (tipos $6,11,16$ y 18 )}

La eficacia de la vacuna tetravalente ${ }^{3}$ fue evaluada en un ECA (en fase IIB*) en 552 mujeres (promedio de edad 20 años) realizado en EEUU, Europa y Brasil que fueron seguidas por más de 48 meses. Los resultados fueron estadísticamente significativos $(p<0,001)$ para las siguientes observaciones: la protección global contra la infección persistente por los tipos 16 y 18 ocurrió en el $100 \%$, \{86\% en el tipo 6 y $89 \%$ en los tipos 16 y 18 . No hubo casos de HPV11. La protección contra CIN ocurrió en el $100 \%$ de las participantes del grupo intervención. Se registraron siete casos de CIN en el grupo placebo. La protección contra todas las verrugas genitales externas por HPV 6-11 ocurrió en $100 \%$ de las participantes, verificándose siete casos en el grupo placebo. La eficacia vaccinal contra los cuatro tipos en conjunto fue de $90 \%$ (IC95\%: 71-97).

En un ECA doble ciego en fase $\mathrm{II}^{*}$, de más de 12.000 mujeres de 16 a 26 años, con dos años de seguimiento se detectaron nueve casos de CIN o adenocarcinoma in situ reportados para el grupo vacuna y 143 en el placebo (94\% de eficacia). Se observaron nueve casos de verrugas genitales externas en el grupo vacuna, versus 174 en el grupo placebo (95\% eficacia). La vacuna fue bien tolerada y no hubo efectos adversos serios. En este momento se encuentran en curso varios ECA internacionales en fase III para ambas vacunas, que en conjunto suman más de 40.000 pacientes y continuarán en los próximos años.

\section{Costo efectividad}

Los estudios identificados sugieren que la estrategia de vacunación en mujeres jóvenes tendría un perfil de costo-efectividad aceptable para los países desarrollados, que oscila entre u\$s 20.000 y 60.000 por año de vida ajustado por calidad de vida $\left(Q A L Y^{\star}\right)$ ganado mientras que no se identificaron estudios en nuestro país.

\section{Políticas de cobertura}

La FDA estadounidense licenció recientemente la vacuna contra HPV. El Comité Asesor sobre prácticas de inmunización (ACIP) del CDC estadounidense ha recomendado la vacuna tetravalente en mujeres de 9 a 26 años. El precio del esquema completo de vacunación rondaría los 360 u\$s, no disponiéndose aún de datos locales.

\section{Conclusiones}

Los ECA identificados mostraron un alto grado de eficacia en mujeres jóvenes para prevenir las lesiones premalignas vinculadas a los tipos de HPV incluidos. Esto podría implicar en el 
largo plazo una reducción de la incidencia de cáncer por el virus HPV. Además la vacuna tetravalente disminuyó la incidencia lesiones vulvares y vaginales, y verrugas genitales. $\mathrm{S}$ bien se desconoce aún la duración de la protección; los anticuerpos protectores persisten al menos durante cuatro años. Se estima que deberán aplicarse refuerzos con intervalos de siete a diez años y es de destacar que los efectos beneficiosos a nivel de la incidencia y prevalencia de cáncer de cérvix en la población general pueden llevar décadas en hacerse ostensibles.

Si bien la vacuna parece constituir un avance mayor en la prevención del cáncer cervical, no reemplaza en el momento actual la necesidad de utilizar estrategias preventivas como el rastreo con PAP, dado que la profilaxis no se extiende a todos los tipos causales de HPV.

Todavía queda por establecerse cual será la mejor estrategia de vacunación a nivel sanitario y la costoefectividad a nive local en comparación con las diferentes intervenciones preventivas.

Resumido de: Pichon Riviere A;Augustovski F;Alcaraz A;Bardach $A$ Colantonio L;García Martí S; Glujovsky D; López A; Regueiro A. Eficacia de la vacuna para el virus del papiloma humano (HPV). Instituto de Efectividad Clínica y Sanitaria. Documentos de Evaluación de Tecnologías Sanitarias, Informe de Respuesta Rápida № 86. Buenos Aires, Argentina. Octubre 2006. Fecha de Última Actualización: 10/2006

\section{Referencias}

1.Koutsky L, Ault K, Wheeler C et.al.A controlled trial of a human papillomavirus type 16 vaccine. N Engl J Med 2002; 347:1645-51). Disponible resumido en castellano: http://www.foroaps.org/files/hp.pdf

2. Harper D, Franco E, Wheeler C, et. al. Efficacy of a bivalent L1 virus like particle vaccine in prevention of infection with human papilloma virus types 16 and 18 in young women: a randomized control trial. Lancet 2004. 364 p. 1757.

3. Villa L. Costa R, Peta C. Prophylactic qudrivalent human papillotavirus (type $6,11,16$ and 18). Li virus like particle vaccine in young womwn: a randomized double blind placebo control multicenter phase II efficacy trial. Lancet Oncol 2005. 6: p. 271.

\section{Cartas de lectores}

\section{Señor \\ Dr. Carlos Musso, Servicio de Nefrología, Hospital Italiano de Buenos Aires.}

Estimado colega

Su artículo: "El médico asistencial, piensa como científico y actúa como artista'" es magnífico.

Si bien impresiona idealizado el planteo de la relación Médico-Paciente, es acertadísima la comparación de principio activo y excipiente para explicar la ciencia y el arte del quehacer médico. Del correcto equilibrio y validez de ambos, según las circunstancias, será la presentación y dependerá la satisfacción de las partes y el éxito de la terapéutica. El razonamiento es muy práctico para tenerlo presente constantemente.

En fin, quiero felicitarlo por el artículo, filosófico y empírico, es de desear encontrar más seguido ese tipo de comentarios. ¡Ah!, también por la bibliografía toda en español... y desde ya para los editores de Evidencia.

Afectuosamente, esperando leer otros.

Dr. Juan Carlos Jiménez

63 años. Médico Clínico, cada vez más inclinado a la práctica ambulatoria juancarlos_gimnez@yahoo.com.ar

Calabozo Venezuela, 21/03/2007

\section{Sr. Director de la Revista Evidencia}

A propósito del comentario del Dr. Yamauchi ${ }^{2}$ sobre la asocición entre el uso del chupete y un menor riesgo de muerte súbita deseo aclarar que, al igual que el chupete, la lactancia materna disminuye el riesgo de Síndrome de Muerte Súbita del Lactante (SMSL) pero mientras el primero es un acto masturbatorio, la segunda es un acto de amor (en la literatura mundial hay innumerables publicaciones al respecto). El chupete causa confusión de pezón y a mayor uso del mismo menor prevalencia de lactancia natural y por ende aumentan las tasas de desnutrición, enfermedad diarreica, respiratoria etc. Es por ello que la Organización Mundial de la Salud y la UNICEF en el "Paso Noveno para una lactancia feliz" desaconsejan el uso de chupetes y biberones. Si adoptamos la posición simplista de aceptar el chupete y el biberón porque son costumbres arraigadas, le estaremos haciendo el juego a las transnacionales de la leche y los hijos del subdesarrollo seguirán engrosando las cifras de mortalidad.

Dr. Carlos Hernández

Jefe del Departamento de Pediatría y Coordinador del Banco de Leche Humana,

Calabozo, Venezuela.

\section{Referencia}

1. Musso C. El médico asistencial piensa como científico y actúa como artista. Evid. Actual. Práct. Ambul. 9(6); 186 Nov-Dic. 2006. Disponible en URL: http://www.foroaps.org/hitalba-pagina-articulo.php?cod_producto=2023\&vol=9\&nr_bi=6\&ano=2006

2. Yamauchi Quintian G. El uso del chupete durante el sueño se asoció a un menor riesgo de muerte súbita del lactante. Evid. Actual. Práct. Ambul. 9(6); 186 Nov-Dic. 2006. Comentado de: Use of a dummy (pacifier) during sleep and risk of sudden infant death syndrome (SIDS): population based case-control study. De-Kun Li, Marian Willinger Diana B Petitti, y col. BMJ 2006; 332; 18-22. PMID: 16339767

Disponible en URL: http://www.foroaps.org/hitalba-pagina-articulo.php?cod_producto=2028\&vol=9\&nr_bi=6\&ano=2006 